\title{
The effect of geographical region of birth on the reproductive performance of the Nguni in southern Mozambique
}

\author{
S. Maciel ${ }^{1}$, A.M. Okeyo ${ }^{2}$, J. Amimo ${ }^{2}$, M.M. Scholtz ${ }^{1,3 \#}$, F.W.C. Neser ${ }^{1}$ \& M. Martins ${ }^{4}$ \\ ${ }^{1}$ Department of Animal Wildlife and Grassland Sciences, UFS, Bloemfontein 9300, South Africa \\ ${ }^{2}$ International Livestock Research Institute, Biotechnology Theme, Nairobi, Kenya \\ ${ }^{3}$ ARC-Animal Production Institute, Irene, South Africa \\ ${ }^{4}$ REMOC, Reprodutores de Mozambique, Lda, Posto Fomento Impaputo, Maputo, Mozambique
}

(Received 23 October 2012; Accepted 19 March 2013; First published online 13 July2013)

Copyright resides with the authors in terms of the Creative Commons Attribution 2.5 South African Licence.
See: http://creativecommons.org/licenses/by/2.5/za/
Condition of use: The user may copy, distribute, transmit and adapt the work, but must recognise the authors and the South African Journal of
Animal Science

\begin{abstract}
The objective of this study was to assess the effect of place of birth on the reproductive performance of two Nguni ecotypes (Nguni and Landim) raised in a sub-tropical environment to enhance strategies for livestock development and restocking programmes within the southern African region. Reproduction data collected between 1994 and 2009 from 301 cows of the Landim $(n=122)$ and Nguni $(n=179)$ ecotypes were analysed. Results indicated that ecotype and place of birth had significant effects on age at first calving (AFC) and calving interval (CI). The means for AFC were 1085 and 1003 days, those for CI were 422 and 436 days, while the calving rate (CR) was $90.0 \%$ and $85.7 \%$ for the Nguni and Landim, respectively. This study demonstrates for the first time a possible genotype by environment interaction between Nguni ecotypes. This might aid future cattle development and restocking programmes in southern Africa, taking into consideration the adaptation of indigenous genotypes and climate change.
\end{abstract}

Keywords: Age at first calving, calving interval, ecotypes, Landim, environment

\# Corresponding author: gscholtz@arc.agric.za

\section{Introduction}

The common genetic background of the different Nguni cattle ecotypes existing in South Africa, Swaziland, Namibia and Zimbabwe is derived from three main migration routes through southern Africa within the Sanga group, and is the result of the interaction between the environment and the genotype over a period of 1200 years (Ramsay, 1988). In Mozambique the Landim, a Nguni ecotype, was numerically the largest indigenous cattle breed (Rocha, 1985; Maciel, 2001), largely distributed among the provinces of Maputo, Gaza and Inhambane in the southern region, where the tsetse fly challenge was low (Rocha et al., 1991). Indigenous to southern African countries and despite being highly adapted to the harsh local environments (Rocha, 1985; Collins-Lusweti, 2000; Muchenje et al., 2008), the different Nguni ecotypes are yet to be fully characterized. Performance of the Landim has only been compared with the Afrikaner at the Chobela Research Station (Catalão \& Syrstad, 1990; Carvalheira et al., 1995) in Maputo province. Unfortunately large numbers of these animals were lost between 1987 and 1992 during the Mozambican civil war. When the civil war ended, Mozambique started a Livestock Restocking Programme importing indigenous cattle breeds from neighbouring countries, especially South Africa, to re-establish the national cattle population and industry. In 1996, nuclei herds of Nguni ecotypes from South Africa and Landim ecotypes from the Chobela research station were placed at the Impaputo Breeding Centre (PFI), on the Swaziland border. The main goals were to establish an "ex-situ" conservation programme and increase cattle numbers in order to meet the national demands for indigenous cattle and their products.

The objective of this study was to assess the effect of place of birth on the reproductive performance of two Nguni ecotypes (Nguni and Landim) raised in a sub-tropical environment to enhance strategies for 
livestock development and restocking programmes within the southern African region, in order to better inform cattle development strategies in Mozambique.

\section{Materials and Methods}

Impaputo Breeding Station (PFI), situated within the Maputo province, is characterized by a subtropical climate within a semi-arid agro-ecological region. The vegetation of PFI is mainly composed of mixed grass species such as Hyparrheania spp., Panicum maximum, Eragrostis superba, Echinochloa spp., Urochloa mozambicensis, Cynodon spp., Rynchelitrum repens and Themeda triandra associated with Acacia spp.

Original Landim and Nguni animals were transferred to PFI from Chobela Research Station (Maputo Province) and different farms in South Africa, respectively. Progeny from both ecotypes were born at this research station. Nguni and Landim were bred in separate herds to ensure purity within the two ecotypes. Animals were commercially managed on natural grasslands with feed supplementation during dry seasons, which consisted of a mixture of milled Sorghum sudanensis and Panicum maximum hay, mixed with molasses and chicken manure.

Two breeding seasons were applied: from January $1^{\text {st }}$ to March $30^{\text {th }}$ and then from July $1^{\text {st }}$ to August $30^{\text {th }}$. A ratio of 25 cows per bull was used. Females that did not calve down at four years of age and did not conceive for two consecutive breeding seasons were culled. Reproduction data, collected between January 1994 and December 2009, from 301 cows of the Landim $(n=122)$ and Nguni $(n=179)$ ecotypes reared at PFI were used in the analysis. The PROC GLM procedure of SAS (2003) was used to analyse reproductive performance data. Sources of variation or factors fitted in the model included breed-type (ecotype), place of birth of foundation animal, parity, Year and Season of calving and Year-Season by ecotype interactions. Place of birth of foundation animal, or origin of the herd, were the Chobela Research Station (Landim), the PFI (Landim and Nguni) and South Africa (Nguni). All parities were numbered. Based on preliminary analysis, reproduction records of cows in parity 7 and higher were pooled. Records for which the cow parity was uncertain were excluded. Least square means (LS means \pm standard errors) for the groups are presented as LS means \pm S.E. As dependent variable, analysis was carried on the age at first calving (AFC) and its fixed effects were herd (South Africa, Chobela and PFI), Year-Season of birth and ecotype (Nguni and Landim). The following statistical model was used:

$\mathrm{Y}_{\mathrm{jklm}}=\mu+\mathrm{h}_{\mathrm{j}}+\mathrm{ys}_{\mathrm{k}}+\mathrm{t}_{\mathrm{l}}+\mathrm{e}_{\mathrm{ijklm}}$

Where $Y_{j k l m}=$ the applicable observation;

$\boldsymbol{\mu}=$ the underlying constant common to all observations;

$\boldsymbol{h}_{\boldsymbol{j}}=$ the fixed effect of the jth herd $(\mathrm{j}=1,2,3)$;

$\boldsymbol{y} \boldsymbol{s}_{\boldsymbol{k}}=$ the fixed effect of the $\mathrm{k}^{\text {th }}$ Year-Season of birth $(\mathrm{k}=1994,1995, \ldots \ldots \ldots .2006)$;

$\boldsymbol{t}_{\boldsymbol{l}}=$ the fixed effect of the $\mathrm{l}^{\text {th }}$ ecotype $(\mathrm{l}=$ Nguni, Landim $)$ and

$\boldsymbol{e}_{i j k l m}=$ the random residual $\mathrm{NID}\left(0, \sigma_{\mathrm{e}}^{2}\right)$.

\section{Results}

The average reproductive performance, represented in LS means \pm SE for AFC, calving interval (CI) and calving rate (CR) for the two ecotypes is presented in Table 1 . The Landim ecotype had a lower AFC ( $P$ $<0.005)$ than the Nguni. Origin of the herd had an effect on AFC $(P<0.05)$, with heifers born at PFI being younger than the ones born at Chobela. Both CI and CR were also influenced by herd origin $(P<0.001)$, with the South African derived cows having longer CI and lower CR than the PFI derived cows (Table 1).

Figure 1 presents the effects of wet and dry seasons on AFC. Year-Season of birth affected AFC ( $P$ $<0.001$ ). Heifers born in dry seasons (May to September) were generally younger at first calving than those born in wet seasons (Oct-April), with exception for heifers born in 2004 dry season (1288.37 \pm 67.53 days). From 2005 onwards AFC decreased and heifers born in dry and wet seasons of 2007 were the youngest at first calving. 
Table 1 LS means \pm SE comparative reproductive performance of Landim and Nguni ecotypes in Impaputo Breeding Centre (PFI) in Mozambique during 1996 to 2009 period

\begin{tabular}{|c|c|c|c|c|c|c|}
\hline \multirow{3}{*}{ Traits } & \multirow{3}{*}{ Overall Mean } & \multicolumn{2}{|c|}{ Ecotypes } & \multicolumn{3}{|c|}{ Origin of the herds } \\
\hline & & \multirow{2}{*}{ Nguni } & \multirow{2}{*}{ Landim } & \multicolumn{2}{|c|}{ Mozambique } & \multirow[t]{2}{*}{ South Africa } \\
\hline & & & & Chobela & PFI & \\
\hline AFC (days) & $1071 \pm 166$ & $1085^{\#} \pm 40$ & $1003^{\#} \pm 39$ & $1129^{\$} \pm 69$ & $965^{\$} \pm 22$ & $1039^{\$} \pm 22$ \\
\hline CI (days) & $432 \pm 85$ & $422 \pm 9$ & $446 \pm 11$ & $428 \pm 12$ & $415^{*} \pm 9$ & $458 * \pm 10$ \\
\hline CR (\%) & $88.1 \pm 14.7$ & $90.0 \pm 1.5$ & $85.7 \pm 1.9$ & $88.9 \pm 2.0$ & $91.5^{*} \pm 1.5$ & $83.4^{*} \pm 1.7$ \\
\hline
\end{tabular}

Note: AFC - Age at First Calving; CI - Calving Intervals; CR - Calving Rates.

Least Square Means (LSM) with the same symbol within the same rows differ significantly from each other at $P<0.0001(*), P<0.005$ (\#) or $P<0.05$ (\$).

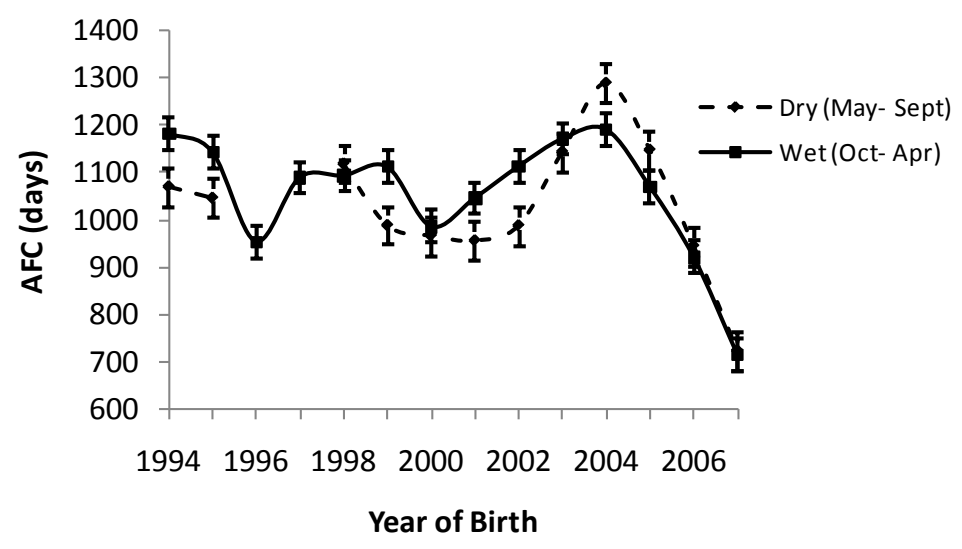

Figure 1 Effects of wet (October to April) and dry (May to September) seasons on age at first calving (AFC) in days of heifers of the Landim and Nguni ecotypes born during 1994 to 2006 period in PFI.

\section{Discussion}

In this study, the combined AFC mean for the Landim and Nguni was $35 \pm 5$ months. The large standard errors are probably due to large differences in age of the foundation herds brought in from Chobela Station and South Africa. In the PFI environment, Landim cows were younger than Nguni at first calving. PFI born cows were the youngest at first calving, especially since 2004 (Figure 1), had the shortest CI and the highest CR. These results are in agreement with those reported by Scholtz \& Lombard (1992) for the Nguni ecotype in South Africa. Under PFI environment, Chobela born cows were the oldest at AFC, but were still about 5.5 months younger than the 41 months reported under Chobela Station conditions. This might be related to the management of animals at PFI, like exposure to the bull after weaning, good quality dry season feed supplementation (good quality hay mixed with molasses and chicken manure). In contrast, Landim heifers at Chobela were submitted to the bull at 18 months age and received only some straw supplementation and molasses during very dry years (Catalão \& Syrstad, 1990; Carvalheira et al., 1995).

\section{Conclusion}

Both ecotypes showed good adaptation to the PFI environment, with heifers that were born at PFI performing better than their mothers who had originated from Chobela and South Africa. Nguni and Landim cows, originated from South Africa and Chobela, had better reproductive results under PFI than what was previously reported in their original environments. For the first time, this study demonstrated the existence of significant genotype-by-environment interactions regarding reproductive traits for the different Nguni ecotypes in Mozambique, thus providing information which can better aid the planning of future cattle development and restocking programmes in southern Africa. 
Epigenetic mechanisms can play a major role in phenotypic diversity in response to environmental conditions. The results of this study may indicate the presence of epigenetics and this stimulated a literature study on the effect of epigenetics on animal production.

\section{Acknowledgements}

This research was possible due to the AWARD research fellowship and collaboration with ILRI. This work is based on research supported in part by Red Meat Research and Development South Africa and the National Research Foundation of South Africa, under grant UID 75121. The Grantholder acknowledges that opinions, findings and conclusions or recommendations expressed in any publication generated by the NRF supported research are that of the authors, and that the NRF accepts no liability whatsoever in this regard.

\section{References}

Carvalheira, J.G.V., Blake, R.W., Pollak, E.J. \& Van Soest, P.J., 1995. Comparison of Landim and Africander cattle in southern Mozambique: II. Female fertility, reproduction and beef off-take. J. Anim. Sci. 73, 3527-3533.

Catalão, D. \& Syrstad, O., 1990. Productivity of the Nguni and Afrikander cattle in Mozambique. Livest. Prod. Sci. 24, 29-36.

Collins-Lusweti, E., 2000. Performance of the Nguni, Afrikander and Bonsmara cattle under drought conditions in North-West Province of Southern Africa. S. Afr. J. Anim. Sci. 30, 33-41.

Maciel, S., 2001. National strategies for the conservation, improvement and utilization of animal genetic resources in smallholder systems. Proceedings of the Planning and Priority Setting Workshop on Animal Genetic Resources in the SADC region. SACCAR, CTA, ILRI. Gaborone, Botswana.

Muchenje, V., Dzama, K., Chimonyo, M., Raats, J.G. \& Strydom, P.E., 2008. Tick susceptibility and its effects on growth performance and carcass characteristics of Nguni, Bonsmara and Angus steers raised on natural pasture. Animal 2, 298-304.

Ramsay, K.A., 1988. Phenotypic selection of the Nguni cattle in different environments in southern Africa. Department of Development Aid. South Africa.

Rocha, A., 1985. Revisão da investigação sobre a avaliação de raças e melhoramento animal em Moçambique. Seminário de Produção Animal. Ministério da Agricultura, 2-7 Dezembro, pp. 86-103 (in Portuguese).

Rocha, A., Starkey, P. \& Dionisio, A.C., 1991. Cattle production and utilisation in smallholder farming systems in Southern Mozambique. Agric. Systems 37, 55-75.

SAS, 2003. SAS/STAT User’s Guide. Version 9.2. ed. SAS Institute Inc., Cary, N.C., USA.

Scholtz, M.M. \& Lombard, P.E., 1992. Prospects of Southern African cattle breeds: The Nguni example. Proc. Aus. Ass. Anim. Breed. Genet. 10, 47-50. 